\title{
Into the Light: Diffusing Ccontroversy and Increasing Transparency in the Faculty Salary Equity Study Process
}

\section{Dr. Carol Elizabeth Marchetti, Rochester Institute of Technology (COE)}

Dr. Carol Marchetti is an Associate Professor of Statistics at Rochester Institute of Technology, where she teaches introductory and advanced undergraduate statistics courses and conducts research in statistics education, deaf education, and team work. She is a co-PI on RIT's NSF ADVANCE IT project, Connect@RIT, and leads grant activities in the Human Resources strategic approach area.

\section{Prof. Margaret B. Bailey P.E., Rochester Institute of Technology (COE)}

Professor Margaret Bailey, Ph.D., P.E. is a Professor of Mechanical Engineering within the Kate Gleason College of Engineering, Rochester Institute of Technology. Dr. Bailey teaches courses and conducts research related to Thermodynamics, engineering and public policy, engineering education, and gender in engineering and science. She is the co-author on an engineering textbook, Fundamentals of Engineering Thermodynamics, which is used worldwide in over 250 institutions. Dr. Bailey is the Principal Investigator (PI) for the RIT NSF ADVANCE Institutional Transformation grant. The goal of this large-scale $(\$ 3.4 \mathrm{M})$, multi-year university-level organizational transformation effort is to increase the representation and advancement of women STEM faculty. At the university level, she serves as Senior Faculty Associate to the Provost for ADVANCE and co-chairs the President's Commission on Women. 


\title{
Into the Light: Diffusing controversy and increasing transparency in the faculty salary equity study process
}

\begin{abstract}
Women are underrepresented in most science, technology, engineering and math (STEM) disciplines within academe and the workforce. In response, the National Science Foundation launched the ADVANCE grant program in the early 2000's to fund efforts which increase the representation of women STEM faculty and academic leaders. Many of the grants funded to date support large-scale comprehensive institutional transformation (IT) projects. In 2012, a large private technical university received an NSF ADVANCE IT grant and set out to strategically launch several initiatives aimed at increasing the representation and advancement of women STEM faculty by removing barriers to resources that support career success and by creating new interventions and resources (NSF ADVANCE 1209115).

This paper reports on one of the initiatives within the overall institutional transformation plan which focuses on a salary gender equity study for pre-tenured and tenured faculty, conducted in a manner in which stakeholders would ideally have a high-level of confidence in its results. A cross-university Resource Allocation Committee (RAC) was created, comprised of administrators and faculty with expertise in statistical analysis, faculty hiring and evaluation processes, institutional data, and gender equity considerations. By providing an inclusive framework for faculty and administrators in the form of a collaborative committee, the grant team aims to increase transparency in the salary equity study process and promote internal dissemination of the methodology used and results observed. This approach has the potential to positively impact faculty perceptions of distributive justice as well as those of procedural justice.

Formation of such a committee is critical to its success: all stakeholders are represented, the group is sized and comprised to minimize risk and maximize transparency, and leaders promote discussion and consensus. This paper demonstrates how the committee framework was able to bridge differences in perspective, address concerns, and serve as a model for sensitive work within the university. Related occurrences of institutional transparency, concurrent with the work of the RAC, will also be discussed.
\end{abstract}

\section{BACKGROUND}

An NSF ADVANCE institutional transformation (IT) project at a large, private university was funded in 2012 (NSF ADVANCE 1209115) to increase the representation, retention, and advancement of women faculty in STEM, including social and behavioral science (SBS) disciplines. The project also focuses on adapting interventions to address the needs of women of color and deaf and hard-of-hearing women faculty. Project objectives include:

1) Refine and strengthen targeted institutional structures, and install practices that promote representation and advancement of women faculty.

2) Improve the quality of women faculty work life, professional development, and incentive/reward structures. 
3) Align institutional, administrative, and informal systems of power and resources to support and sustain progress by shaping the political frameworks that impact representation and advancement of women.

4) Enhance the working environment and support career advancement for women faculty using symbolic measures that emphasize issues of meaning within the organization.

Other concurrent transformations occurring within the university include a steady and yet sustainable student-body growth, increased student selectivity, academic program growth, and increased research productivity and outcomes from the faculty.

Prior to the start of the institutional transformation grant, the project team conducted a three-year self-study (NSF ADVANCE 0811076) from 2008-2011 that revealed areas of concern and opportunity for the university ${ }^{[1]}$. Some of the findings include:

- Barriers existed for women STEM faculty around the areas of career navigation, climate, and work/life balance.

- The percent of women STEM faculty applicants was below the national pool of availability.

- Upon hire, women faculty received less credit towards tenure and were less likely to be hired at a rank above assistant professor.

- The percent of women STEM faculty was found to be below national averages.

- The attrition rate of women faculty was found to be nearly twice that of their male colleagues.

- A 2010 faculty salary study found unexplained salary differences along gender lines.

Historically, salaries for women have been lower than those for men in many fields ${ }^{[2,3,4,5]}$, so the 2010 finding was not surprising. At this time, the university established funding to address salary inequities, hence further analysis would be needed to determine the success of the redress process. In 2012, the funded institutional transformation project commenced, including the effort for a comprehensive faculty salary equity study. NSF provides a toolkit to grantees describing the basic components of the required salary equity study ${ }^{[6]}$ and the American Association of University Professors has extensive guidelines ${ }^{[7]}$ for such studies.

However, stakeholders involved in conducting a salary equity study and faculty interested in its outcomes often have differing backgrounds and perspectives, and don't always speak the same "language". In addition, if no results or partial and unclear results are shared from the salary gender equity study, the university may negatively impact faculty perceptions of distributive justice (which asks "are salaries fair and equitable, on average") ${ }^{[8]}$ and procedural justice (asking, "is the process used in determining equity fair and satisfying in itself") ${ }^{[9]}$. Also some may be concerned about uncovered issues surfacing for which resources are not available to fully address. Hence, universities may feel that it is safest to be non-transparent and silent in regards to gender equity faculty salary studies. At the same time, faculty may feel that the lack of information is due to problems that the university wants to conceal. A possible solution is for faculty and administration to form a productive collaboration in order to conduct the study. This paper examines the framework for a collaboration to obtain a faculty salary gender equity study in which all stakeholders could have high confidence in the process undertaken and the results. 


\section{METHODOLOGY}

At the time that the project began in 2012, the university had developed an annual practice of conducting faculty and staff salary studies using the services of an external consulting firm. The purpose of these studies was to predict individual salaries by constructing a model with the highest overall explanatory measure. Within such a model, the number of variables and their inter-relationships is of secondary importance. Therefore, the effect of individual variables within the model is not important, and there is no need to interpret their coefficients. In building a model to evaluate salary equity by gender, the AAUP ${ }^{[7]}$ cautions against using too many variables so that the coefficients for each variable provide meaning. Determining appropriate methodology for statistical model creation often includes differences of opinion among data analysts, and a rich, productive discussion and dialogue can enhance overall model design considerations.

To create a scenario where such a dialogue could readily occur, the Resource Allocation Committee (RAC) was formed. The RAC created a charge, endorsed by the upper administration, to direct and oversee a salary-equity study of tenured and pre-tenured faculty conducted by an external consultant (see Appendix for charge). The RAC was led by the IT grant's principal investigator and a university vice president. Membership of the RAC included administrators and faculty with expertise in statistical analysis, faculty hiring and evaluation processes, institutional data, and gender equity considerations. The resulting group had the expertise needed to carry out the charge and quickly took on the characteristics of a "conscientious" team. They devised a plan and timeline to guide their efforts and they developed deliberate processes to promote productive dialogue where all voices could be heard and all ideas could be vetted. Questions that drove their initial efforts included "what elements should a faculty salary equity study include?" and "how should an external data analyst/consultant be selected"?

The RAC developed a Request for Proposals (RFP) to conduct the faculty salary equity study using the standard template provided by the university purchasing department. The RFP contained several sections shown in Table 1. Some of the sections in Table 1 (e.g. nondiscrimination compliance) contain standard wording completed by the purchasing department, some were clear cut to create (e.g. project schedule), and others (for example, evaluation criteria for operating requirements) required extensive discussion and collaboration to reach consensus among the RAC members.

After the RFP was completed and prior to its issuance, the purchasing department suggested creating a detailed rubric for evaluation of proposals. This suggestion drew strong agreement from the committee and RAC members found this exercise to be valuable. It provided a final opportunity to closely review the RFP and assign significance or weights of importance to each portion of the RFP while setting guidelines for evaluation. To reach consensus on the rubric, the RAC members considered their inherent differing perspectives and collaborated to create a highquality rubric that proved to be effective at guiding the RFP review process. In addition, creating the rubric before solicitation was key to minimizing potential biases in the evaluation of proposals. 


\section{Table 1. Sections of the Request for Proposal (RFP)}

\begin{tabular}{|r|l|}
\hline$\#$ & Information \\
\hline 1. & Introduction \\
\hline 2. & Background Information \\
\hline 3. & Project Schedule \\
\hline 4. & Contract Award in Best Interest \\
\hline 5. & Non-Discrimination Compliance \\
\hline 6. & Confidentiality \\
\hline 7. & Instructions for Submittal \\
\hline 8. & Evaluation Criteria \\
& $\begin{array}{l}\text { a. Pricing } \\
\text { b. Operating Requirements } \\
\end{array}$ \\
& $\begin{array}{l}\text { c. Quality Metric/Performance Metrics } \\
\text { d. Evidence of Business Performance }\end{array}$ \\
& e. Sustainability (Green Strategy) \\
& f. Terms and Conditions \\
\hline
\end{tabular}

Finally, before issuing the RFP to possible bidders, the committee developed a list of potential consultants, drawing from their individual professional networks. At that point, the university purchasing department distributed the RFP, coordinated a conference call involving the RAC to answer questions, and collected proposal submissions.

With the rubric in place, RAC members had guidelines by which to evaluate the proposals that were received. While this did not ensure complete agreement, it did provide a framework for discussions. Proposals were evaluated using the agreed-upon metrics in the rubric and, in turn, consultants could only be evaluated by the materials they submitted.

Committee member preferences started to coalesce around one proposal, but not all were ready to award a contract. Because the RFP asked for references, we were able to obtain additional helpful information from these sources. Speaking to former clients provided valuable information about the process and product we hoped to receive. In fact, some of the feedback obtained helped to shape the final contract.

Once the contract was awarded, the RAC designated a subset of members to work collaboratively with the consultant to provide data and institute-specific background, regularly review work-in-progress, and guide the analysis to maximize the utility of the results. This involved weekly conference calls followed by updates to the full RAC, and consultation with the full RAC on any issues where a difference of opinion required further discussion and an opportunity to expand common ground.

\section{RESULTS}

Salary analyses conducted by the university prior to creation of the RAC used a different approach to statistical methodology and did not include faculty collaboration or input during the salary study process. The process was not made transparent to faculty and the results of the 
analyses were not generally shared with the faculty. Several opportunities existed to build more transparency in this overall process and ideally to create a collaborative group of faculty and administrators who could together have a deep understanding of the statistical study and a highlevel of confidence in the study's outcomes. The current process and methodology described in this paper focus on this refined approach at conducting a faculty gender equity salary study.

Initial impressions from the perspectives of several RAC members were that the committee framework and collaborative process resulted in many positive outcomes. An objective measure in regards to the RAC effectiveness is that a faculty salary equity study analysis and report were completed. Working together in a larger group provided checks and balances that built trust in the process and outcomes. It also reduced the perceived risk individuals felt from involvement in a sensitive initiative such as this.

Reaching consensus among committee members required discussion of differences of opinion. Many questions were asked and answered, allowing for a better understanding of the broad perspectives of committee members, and often informed the processes. Ample discussion often occurred over lunch meetings where food was provided and time allocated appropriately. This opened the process for examination and thus increased transparency, built collective knowledge of many aspects related to salary equity, increased confidence in the process (procedural justice), and increased confidence in and understanding of the study's outcomes (distributive justice). In particular, the Advance team is now able to endorse and fully understand the validity of the salary equity study results.

Because of this confidence, the university administration has committed to disseminating the executive summary of the salary study report. With the support of the Advance team, the university can more easily disseminate the results to faculty, along with information about salary processes at the university, so that faculty and department heads have a basis for productive dialogues around salary. Prior to the start of the 2012 IT project, the university had already committed to conducting annual faculty salary studies, and is considering the possibility of continuing this practice in a collaborative nature, sharing the process and results with faculty.

Survey data on faculty perceptions of the salary equity study and processes would reveal whether the increased transparency of the RAC process improved general faculty confidence and understanding of the salary process. We do not have this data at present, but such a survey is currently being considered by the RAC.

Related positive outcomes during the timeframe of the salary study included the release of faculty salary benchmark data, by discipline and rank, on a secure web site. In addition, the Academic Senate undertook a charge to review university policies related to faculty salary, with the goal of increased transparency. Such efforts are important to faculty perceptions of equity, particularly for women faculty ${ }^{[11]}$.

\section{FUTURE WORK}

Because performance and faculty rank are both significant factors in faculty salary ${ }^{[3,4,10]}$, addressing processes for performance appraisals and promotion to full professor are key to salary 
equity. It is important to consider the processes from both distributive and procedural justice perspectives because institutions often lack established policies for filing complaints about the annual performance appraisal process ${ }^{[11]}$ and female faculty believe they need more evidence than their male colleagues to be promoted to full professor ${ }^{[12]}$.

A more complete evaluation is currently under consideration to examine the possible impact (positive and negative) associated with the salary gender equity study conducted by the RAC, its subsequent report and dissemination, and the university's activities to build transparency and understanding around benchmark data. In this evaluative exercise, possible changes to perceived levels of distributive and procedural justice by various stakeholders will be examined.

This type of working group should be considered in a variety of situations where tensions are high and many constituents have a stake in the results. Recently, for example, on one campus student access to faculty teaching evaluations was a controversial topic on campus with heated email exchanges. Reaching out and bringing interested parties together resulted in a collaborative solution, and only two meetings were required. It is important that all stakeholders are represented for this process to be successful.

\section{ACKNOWLEDGEMENTS}

This material is based upon work supported by the National Science Foundation under Grants 0811076 and \#1209115. The researchers wish to express their gratitude for the support of this project. Any opinions, findings, and conclusions or recommendations expressed in this material are those of the authors and do not necessarily reflect the views of the National Science Foundation.

\section{REFERENCES}

[1] Margaret Bailey, S. B., Elizabeth DeBartolo, Carol Marchetti, Sharon Mason, Jacqueline Mozrall, Maureen Valentine (2012). "EFFORT - Establishing the Foundation for Future Organizational Reform and Transformation at Rochester Institute of Technology: Report to the Rochester Institute of Technology Community" http://nsfadvance.rit.edu/effort/ (accessed January 30, 2016).

[2] Lips, H. M. (2013). The gender pay gap: Challenging the rationalizations. Perceived equity, discrimination, and the limits of human capital models. Sex Roles, 68(3-4), 169-185.

[3] Jagsi, R., Griffith, K. A., Stewart, A., Sambuco, D., DeCastro, R., \& Ubel, P. A. (2012). Gender differences in the salaries of physician researchers. JAMA, 307(22), 2410-2417.

[4] Ginther, D. K., \& Hayes, K. J. (2003). Gender differences in salary and promotion for faculty in the humanities 1977-95. Journal of Human Resources, 38(1), 34-73.

[5] Fuller, R., \& Schoenberger, R. (1991). The Gender Salary Gap: Do Academic Achievement, Internship Experience, and College Major Make a Difference?.Social Science Quarterly, 72(4), 715-26.

[6] Frehill, L.M., Cannavale, C.J., Kehoe, P., Lange, S.E., Malley, J., Meader, E., Sheridan, J., Stewart, A. and Sviglin, H. (2005). Toolkit for reporting progress toward NSF ADVANCE: Institutional transformation goals. Retrieved from 
www.advance.vt.edu/documents/other/advance_indicators_toolkit.pdf (Accessed January 30, 2016).

[7] Haignere, L. (2002). Paychecks: A guide to conducting salary-equity studies for higher education faculty. American Association of University Professors, 1012 Fourteenth Street, NW, Suite 500, Washington, DC 20005.

[8] Estlund, C. (2014). Extending the Case for Workplace Transparency to Information About Pay. UC Irvine L. Rev., 4, 781.

[9] Cloutier, J., \& Vilhuber, L. (2008). Procedural justice criteria in salary determination. Journal of Managerial Psychology, 23(6), 713-740.

[10] O'Keefe, S., \& Wang, T. C. (2013). Publishing pays: Economists' salaries reflect productivity. The Social Science Journal, 50(1), 45-54.

[11] Monroe, K., Ozyurt, S., Wrigley, T., and Alexander, A. (2008). Gender equality in academia: Bad news from the trenches, and some possible solutions. Perspectives on Politics, 6(2), pp. 215-233.

[12] Roos, P.A. (2008). Together but unequal: Combating gender inequity in the academy. Journal of Workplace Rights, 13(2), pp. 185-199. 


\section{ADVANCE Resource Allocation Committee}

\section{Proposed Committee Members:}

- Co-Chair: University VP

- Co-Chair: ADVANCE PI

- ADVANCE co-PI's

- Academic Affairs Representatives

- Institutional Research Representatives

- Human Resources Representatives

- Department Head

- Statistics Faculty

\section{Charge}

The NSF ADVANCE program lays out four research questions ${ }^{1}$ as a framework for universities to document progress towards institutional transformation. One of these questions, "What is the allocation of resources for science and engineering faculty?", requires the following data:

- Study of salaries of men and women faculty (with additional controls such as department, rank, years in rank)

- Study of space allocation of STEM faculty by gender (with additional controls such as department, etc.)

- Study of start-up packages of newly hired faculty by gender (with additional controls such as field/department, rank, etc.)

In year 2 of the ADVANCE Institutional Transformation grant (SEP 2013 - AUG 2014), the ADVANCE Resource Allocation Committee will direct and oversee a salary-equity study of tenured and tenure-track (T-TT) faculty. The goal is to understand the direct and indirect effects that gender may have on faculty salary. It is recommended that the following sources guide the salary study:

- Funded NSF ADVANCE Institutional Transformation Proposal

- Toolkit for Reporting Progress Toward NSF ADVANCE: Institutional Transformation Goals

- AAUP Paychecks: A Guide to Conducting Salary-Equity Studies for Higher Education

\section{The Committee's plan of work for the current grant year may include:}

1. Benchmarking best practices from other ADVANCE Institutions

2. Process: Working w/Consultant or Conducting Study In-house

3. Process: Data Verification Process

4. Process: Input, Data Verification/preprocessing, Analysis, Output, Reporting

5. Develop a Communication Plan for the committee's work

6. Develop a Contract w/Consultant or Agreement with Internal Provider

7. Develop an Analysis Request and Data Verification Request

8. Review Analysis

9. Create Report for Dissemination

10. Disseminate

${ }^{1}$ Toolkit for Reporting Progress Toward NSF ADVANCE: Institutional Transformation Goals 